\title{
Preparation and characterization of anti-HIV nanodrug targeted to microfold cell of gut-associated lymphoid tissue
}

This article was published in the following Dove Press journal:

International Journal of Nanomedicine

18 September 2015

Number of times this article has been viewed

\author{
Upal Roy',* \\ Hong Dingl,* \\ Sudheesh Pilakka- \\ Kanthikeel' \\ Andrea D Raymond \\ Venkata Atluri' \\ Adriana Yndart ${ }^{1}$ \\ Elena M Kaftanovskaya ${ }^{2}$ \\ Elena Batrakova ${ }^{3}$ \\ Marisela Agudelo' \\ Madhavan Nair' \\ 'Center for Personalized \\ NanoMedicine, Institute of \\ Neurolmmune Pharmacology, \\ Department of Immunology, \\ ${ }^{2}$ Department of Human and Molecular \\ Genetics, Herbert Wertheim College \\ of Medicine, Florida International \\ University, Miami, FL, USA; ${ }^{3}$ UNC \\ Eshelman School of Pharmacy, The \\ University of North Carolina at \\ Chapel Hill, Chapel Hill, NC, USA \\ *These authors contributed equally \\ to this work
}

Correspondence: Upal Roy

Center for Personalized NanoMedicine, Institute of Neurolmmune Pharmacology, Department of Immunology, Herbert Wertheim College of Medicine, Florida International University, II 200 SW 8th

Street, Miami, FL 33199, USA

Tel +l 3053487656

Email uroy@fiu.edu

Madhavan Nair

Center for Personalized NanoMedicine, Institute of Neurolmmune Pharmacology, Department of Immunology, Herbert Wertheim College of Medicine, Florida International University, II 200 SW 8th Street, Miami, FL 33199, USA

Email nairm@fiu.edu
Abstract: The human immunodeficiency virus 1 (HIV-1) still remains one of the leading life-threatening diseases in the world. The introduction of highly active antiretroviral therapy has significantly reduced disease morbidity and mortality. However, most of the drugs have variable penetrance into viral reservoir sites, including gut-associated lymphoid tissue (GALT). Being the largest lymphoid organ, GALT plays a key role in early HIV infection and host-pathogen interaction. Many different treatment options have been proposed to eradicate the virus from GALT. However, it becomes difficult to deliver traditional drugs to the GALT because of its complex physiology. In this regard, we developed a polymer-based Pluronic nanocarrier containing anti-HIV drug called efavirenz (EFV) targeting Microfold cells (M-cells) in the GALT. M-cells are specialized epithelial cells that are predominantly present in the GALT. In this work, we have exploited this paracellular transport property of M-cells for targeted delivery of Pluronic nanocarrier tagged EFV, bioconjugated with anti-M-cell-specific antibodies to the GALT (nanodrug). Preliminary characterization showed that the nanodrug (EFV-F12-COOH) is of $140 \mathrm{~nm}$ size with 0.3 polydispersion index, and the zeta potential of the particles was $-19.38 \pm 2.2 \mathrm{mV}$. Further, drug dissolution study has shown a significantly improved sustained release over free drugs. Binding potential of nanodrug with M-cell was also confirmed with fluorescence microscopy and in vitro uptake and release studies. The anti-HIV activity of the nanodrug was also significantly higher compared to that of free drug. This novel formulation was able to show sustained release of EFV and inhibit the HIV-1 infection in the GALT compared to the free drug. The present study has potential for our in vivo targeted nanodrug delivery system by combining traditional enteric-coated capsule technique via oral administration.

Keywords: HIV-1, drug delivery, GALT, M-cells

\section{Introduction}

The introduction of highly active antiretroviral therapy (HAART) has significantly reduced human immunodeficiency virus (HIV) infection-related morbidity and mortality. However, a major limitation in this treatment is lifelong daily drug dosing regimens and concomitant side effects. ${ }^{1,2}$ The gastrointestinal tract plays a key role in not only early HIV infection in establishing viral reservoirs in gut-associated lymphoid tissue (GALT) but also disease pathology. ${ }^{3}$ Moreover, most of the anti-HIV drugs have variable penetrance into viral reservoir organs such as central nervous system and GALT. As a consequence, viral persistence remains an existing issue despite widespread HAART usage. ${ }^{1,48}$ Many different treatment options have been proposed to eradicate the virus from GALT. However, it has become increasingly difficult to design drugs that would be targeted toward the GALT ${ }^{9}$ due to its complex physiology. Therefore, the identification of the means to improve the bioavailability and therapeutic index of

submit your manuscript $\mid$ www. dovepress.con 
HAART drugs to eradicate the GALT reservoir is of great importance. A targeted delivery is an ideal mean to reach the GALT and remote lymphatic tissue where conventional drugs have failed to reach due to its insolubility and inaccessibility to lymph nodes. In this regard, microfold cells (M-cells) from the small intestine are an excellent cellular target to deliver anti-HIV drug to the GALT.

The epithelium that lines the human gut is impermeable to macromolecules/microorganisms except Peyer's patches, where the follicle-associated epithelium contains M-cells. Many pathogenic organisms exploit M-cells to cross the digestive epithelial barrier. ${ }^{10}$ The M-cells effectively bind, transport, and deliver macromolecules to the cells underlying the mucosal immune system. They mainly serve as antigen sampling cells that take the foreign molecule from the gut and transport it to the underlying lymphoid tissue. This unique characteristic of M-cells has been utilized as a potential target for oral vaccines. ${ }^{11,12}$ Since they possess a high transcytotic capacity to transport broad range of materials, M-cells have been investigated for nanoparticle transport. However, possible gastrointestinal digestion and poor intestinal absorption of nanoformulations leads to low bioavailability. ${ }^{13}$ Therefore, new oral formulations have to be developed to tackle these difficulties. In this regard, one delivery strategy can be designed to encapsulate the drug in some drug carrier (liposome, Pluronic block copolymer micelles, etc) to prevent the enzymatic digestion and facilitate the M-cell-based uptake.

The objective of this study is to develop a long-acting nanoformulated antiretroviral drug to improve the existing antiretroviral therapy. At our end, we have developed a Pluronic nanocarrier with incorporated efavirenz (EFV) drug. This formulation is further bioconjugated with a universal M-cell-specific marker anti-glycoprotein 2 (GP2) (together called nanodrug) to target it toward GALT. Being one of the potent drugs preventing mother to child transmission of HIV, EFV drug has been investigated for pharmacokinetic variability, therapeutic effects, and toxicity among different patient populations. ${ }^{14-16}$ It has been observed that a very strict pharmacological concentration is a must in order to avoid virologic failure and tissue toxicity. Therefore, it was worth investigating the nanoformulation of EFV for anti-HIV activity and toxicity in GALT. An in vitro model of M-cell co-culture system was used to characterize this formulation for its cytotoxicity, drugloading capacity, sustained release, and anti-HIV activity. In future, this nanoformulation will be encapsulated into an enteric coating capsule for in vivo drug delivery study targeted to GALT.

\section{Materials and methods Materials}

Pluronic F127 (F127), maleic anhydride, toluene, pyridine, diethyl ether, $N$-(3-dimethylaminopropyl)- $N^{\prime}$ ethylcarbodiimide hydrochloride, pepsin, and high-performance liquid chromatography (HPLC) water were used as received from Sigma-Aldrich Co. (St Louis, MO, USA). The tetrazolium compound [3-(4,5-dimethylthiazol-2-yl)-5-(3carboxymethoxyphenyl)-2-(4-sulfophenyl)-2H-tetrazolium, inner salt; MTS] was purchased from Promega Corporation (Fitchburg, WI, USA). Transwell polycarbonated filter plate with insert ( 24 well with pore diameter $0.4 \mu \mathrm{m}$ ) was purchased from Corning Costar (New York, NY, USA). AntiGP2 antibodies were purchased from MBL (Nagoya, Japan). Isotype antibodies were purchased from BD Biosciences (San Jose, CA, USA). Human colon carcinoma Caco-2 cell line (passages 20-30) and human Burkitt's lymphoma Raji B line (passages 30-40) were purchased from American Type Culture Collection (ATCC) (Manassas, VA, USA) and used within the passage mentioned in the parentheses. EFV drug powder and all other chemicals were obtained from Sigma-Aldrich Co.

\section{Assay instruments and characterizations}

Transmission electron microscopy (TEM) was used to determine the size and shape of the prepared F127COOH-EFV micelles by Phillips CM-200 $200 \mathrm{kV}$ transmission electron microscope at an accelerating voltage of $80 \mathrm{kV}$. A 90Plus Particle Size Analyzer (Brookhaven Instruments Corporation, Holtsville, NY, USA) was used to measure the hydrodynamic size and zeta potential of the F127COOH-EFV. A microplate reader (Synergy HT, multi-mode microplate reader; BioTek, Winooski, VT, USA) was used to measure the absorbance of samples related to cell viability. A fluorescence spectroscopy technique based on a pyrene probe using a Shimadzu spectrofluorometer (RF-5301PC; Shimadzu, Kyoto, Japan) was applied to estimate the critical micelle concentration (CMC) of the F127COOH micelles.

\section{Methods}

\section{Synthesis of carboxylated functional Pluronic FI 27 ( $\mathrm{FI} 27 \mathrm{COOH})$}

As shown in Figure 1A, carboxylated ABA triblock copolymer F127 (F127COOH) was synthesized according to the literature with minor modification. ${ }^{17}$ Briefly, maleic anhydride 


\section{A}<smiles>CC(COCCOCCO)CC(C)(C)COCCO</smiles>

$\mathrm{F} 127\left(\mathrm{EO}_{98} \mathrm{PO}_{67} \mathrm{EO}_{98}\right)$<smiles>O=C1C=CC(=O)O1</smiles>

Pyridine/toluene

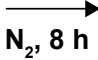

Maleic anhydride<smiles>CC(C)(COCCOCCOC(=O)C=CC(=O)O)COCCOC(=O)C=CC(=O)O</smiles>

Carboxyl functional F127 (F127COOH)

B

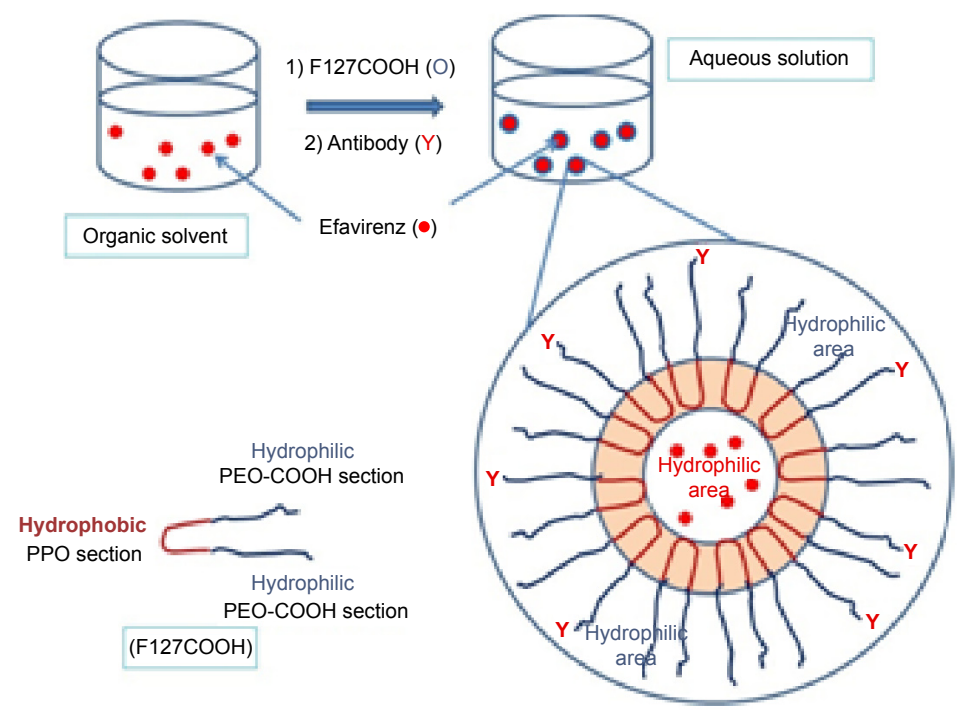

Figure I (A) The illustration of synthetic routine of carboxyl-functionalized triblock copolymer FI27 (FI27COOH). (B) The efavirenz-loaded FI27COOH micelles bioconjugated with antibody.

Abbreviations: EO, ethylene oxide; PEO, polyethylene oxide; PO, propylene oxide; PPO, polypropylene oxide.

$(1.93 \mathrm{~g}, 19.5 \mathrm{mmol})$ was added to a solution of F127 (25.0 g, $1.95 \mathrm{mM})$ in a mixed solvent of toluene $(100 \mathrm{~mL})$ and pyridine $(5 \mathrm{~mL})$. The whole mixture was stirred for 8 hours at the room temperature (RT) under a nitrogen stream. After purification by precipitation from excessive diethyl ether thrice, $21.3 \mathrm{~g}(85 \%)$ of $\mathrm{F} 127 \mathrm{COOH}$ as a light brown solid was obtained.

\section{Preparation of drug-loaded Pluronics with antibodies conjugation (FI27-COOH-EFV-GP2 or nanodrug)} In a typical experiment, hydrophobic drug of EFV dissolved in chloroform $(2.0 \mathrm{mg}$ ) was mixed with $\mathrm{F} 127 \mathrm{COOH}$ in chloroform $(20 \mathrm{mg})$ at a weight ratio of 1:10. The mixture was gently stirred for 5 minutes, and a rotary vacuum evaporator with a water bath of $35^{\circ} \mathrm{C}$ was applied to evaporate the organic solvent. The deposited film on the vials was hydrated with $1.0 \mathrm{~mL}$ of HPLC water. The resulting clear dispersion was kept at RT for further use.
The $200 \mu \mathrm{L}$ of $\mathrm{F} 127 \mathrm{COOH}-\mathrm{EFV}$ aqueous solution obtained in the previous step was incubated with $20 \mu \mathrm{L}$ of $N$-(3-dimethylaminopropyl)- $N$-ethylcarbodiimide hydrochloride solution $\left(1.92 \mathrm{mg} / \mathrm{mL}\right.$ in water, $\left.1.04 \times 10^{-6} \mathrm{~mol}\right)$ for 5-10 minutes, and then, $14 \mu \mathrm{L}$ solution of anti-GP2 antibodies $\left(0.5 \mathrm{mg} / \mathrm{mL}, 4.67 \times 10^{-11} \mathrm{~mol}\right)$ was added.$^{18}$ After 1.5 hours of incubation, the antibodies conjugated F127COOH-EFV nanoparticles spun down at 10,000 rpm for 10 minutes and then redispersed in $220 \mu \mathrm{L}$ of phosphate-buffered saline (PBS) for further application.

\section{Transmission electron microscopy}

The size of the F127COOH-EFV micelles was determined using negative staining technique of TEM. In brief, one drop of F127COOH-EFV micelles was spread on carbon support film on 400 mesh Cu grids (type B; Ted Pella, Inc., Redding, CA, USA). The grid samples were examined using TEM imaging as explained earlier. The samples on the grids were 
negatively stained with phosphotungstic acid $(2.0 \%, \mathrm{w} / \mathrm{v}$; $\mathrm{pH}$ 6.4) and dried at RT.

\section{Particle size and zeta potential}

The hydrodynamic radius, size distribution, and surface charge measurements of $\mathrm{F} 127 \mathrm{COOH}-\mathrm{EFV}$ were carried out at $25^{\circ} \mathrm{C}$ using dynamic laser scattering (DLS) (90Plus Particle Size Analyzer). Scattered light was detected at a $90^{\circ}$ angle and at a temperature of $25^{\circ} \mathrm{C}$. Hydrodynamic size was expressed as mean \pm SEM of triplicate measurements. The aggregation stability of the nanoparticles in a $10 \mathrm{mM}$ phosphate buffer was examined over 25 days.

\section{Colloid and physiological stability}

The nanocarriers were stored at $4^{\circ} \mathrm{C}$, and the durability of their structural integrity was evaluated by measuring their size for up to 28 days. Further, their stability in blood fluid was assessed by measuring their size in an in vitro closed circulatory system at $37^{\circ} \mathrm{C}$ for up to 28 hours. This closed circulation system was set up using a bidirectional, self-priming peristaltic pump (Mini Pump Peristaltic Pump Variable Flow C-2 Lab Pump; Thermo Fisher Scientific, Waltham, MA, USA). The nanoformulation was allowed to circulate in a $0.8 \mathrm{~mm}$ capillary 120 times at a flow rate of $1 \mathrm{~mL} / \mathrm{min}$. The circulating medium was prepared with 5\% dextran-500 (catalog no 50-247-495; Thermo Fisher Scientific) in PBS, which gave a viscosity equivalent to that of blood (4.5 cP). Samples were collected after 10, 30, 60 , and 120 circulations and subjected to size analysis by DLS. ${ }^{19}$

\section{Dissolution of the nanoformulation}

A $2 \mathrm{~mL}$ solution of F127COOH-EFV nanoparticles $(0.5 \mathrm{~mL}$, concentration: $2 \mathrm{mg} / 20 \mathrm{mg}$ ratio drug/F127COOH) was placed into a dialysis bag (molecular cutoff: $6 \mathrm{kDa}$ ), sealed, and put into a tube filled with $30 \mathrm{~mL}$ dissolution solution (composition: $0.1 \%$ Tween 20 aqueous solution). The tube was placed on a $37^{\circ} \mathrm{C}$ shaker at $150 \mathrm{rpm}$. At each time point ( 0 minute, 5 minutes, 10 minutes, 15 minutes, 30 minutes, 60 minutes, 2 hours, 4 hours, 8 hours, 1 day, 2 days, 4 days, 6 days, 8 days, 10 days, 12 days, and 14 days), $100 \mu \mathrm{L}$ of solution was taken out from the tank when the drug was releasing out of the dialysis bag and $100 \mu \mathrm{L}$ of fresh dissolution was refilled. The same concentration of free drug was used as a control.

At the last time point, the drug concentration was determined by HPLC $(150 \mathrm{~mm} \times 4.6 \mathrm{~mm}$ column, injection volume: $20 \mu \mathrm{L}$, detection wavelength: $215 \mathrm{~nm}$, temperature of performance: $30^{\circ} \mathrm{C}$, retention time: 19.827 minutes).

\section{In vitro $\mathrm{M}$-cell co-culture model}

The Caco-2 cells were cultured in Dulbecco's Modified Eagle's Medium (DMEM) (Thermo Fisher Scientific) with $20 \%$ (v/v) fetal bovine serum, and Raji cells were cultured in RPMI 1640 medium supplemented with 10\% (v/v) +1\% penicillin and streptomycin solution. The in vitro M-cell coculture model was adopted from previous studies. ${ }^{11,13}$ Briefly, $0.1 \mathrm{~mL}$ and $1.5 \mathrm{~mL}$ DMEM complete media were added to the apical and basolateral sides of the 24-well Transwell plates, respectively. The Caco- 2 cells $\left(5 \times 10^{5}\right.$ cells/well $)$ were seeded on the apical sides of the Transwell, and the medium of the apical side was changed every other day for next 14 days of culture. Raji cells $\left(3 \times 10^{5}\right.$ cells/well) were suspended in complete RPMI 1640/DMEM (1:2) mixture and then added to the basolateral chamber of the Transwell; co-culture was maintained for 12 days. The integrity of the epithelial barrier was measured by transendothelial electrical resistance using Millicell-ERS microelectrodes (EMD Millipore, Billerica, MA, USA). ${ }^{20}$ Caco- 2 cells were also cultured without Raji cells to serve as a control.

\section{Flow cytometry}

M-cells or differentiated Caco-2 cells were scrapped out of the Transwell culture and washed with PBS. M-cells were further washed with flow-cytometry (fluorescenceactivated cell sorting [FACS] ) buffer (PBS, 5\%-10\% fetal bovine serum, $0.1 \% \mathrm{NaN}_{3}$ [sodium azide]), probed with the anti-GP2 antibodies ( $2 \mu \mathrm{g} / \mathrm{mL})$, and incubated at RT for 20 minutes in the dark. Cells were then washed with the FACS buffer to remove the unbound antibodies, fixed with 2\% paraformaldehyde, and analyzed by FACS (Accuri C6; BD Biosciences). Caco-2 and Raji cells were gated for GP2 based on the isotype gating on respective cells.

\section{Immunofluorescence staining of M-cells}

Caco-2 cells cultured on coverslip were added to Raji cells seeded in Transwell culture plate. After the incubation, the Caco-2 monolayer was washed several times with PBS and fixed with $4 \%$ paraformaldehyde for 30 minutes at $4{ }^{\circ} \mathrm{C}$. Further, the cells were washed with $0.1 \%$ Triton X-100 in PBS for three times for 5 minutes each. Primary antibodies (anti-GP2 antibodies $2.5 \mu \mathrm{g} / \mathrm{mL}$ ) were added in PBS with $0.1 \%$ Triton X-100 for 1 hour. The cells were washed three times with $0.1 \%$ Triton X-100 in PBS for 5 minutes. After washing, secondary antibodies (Alexa Fluor 488 goat anti 
mouse antibodies; $10 \mu \mathrm{g} / \mathrm{mL}$ ) were added and incubated at RT for 45 minutes. Cells were washed again with $0.1 \%$ Triton $\mathrm{X}-100$ in PBS. Coverslips were mounted on the slides with ProLong ${ }^{\circledR}$ Gold antifade reagent (Invitrogen, Carlsbad, CA, USA) before proceeding for fluorescence microscopy. The stained cells were examined using a fluorescent Axio Imager. M2 microscope and AxioCam MRm camera set (Carl Zeiss Meditec AG, Jena, Germany).

\section{Cellular uptake of fluorescent nanodrug}

To examine the M-cell-mediated drug transport in the in vitro system, a specially designed nanoformulation was prepared. For this purpose, F127-COOH-EFV-GP2 was further conjugated with fluorescent dye Alexa Fluor 610X NHS (N-hydroxysuccinimide) ester (Invitrogen) ${ }^{21}$ before the experiment. The uptake of fluorescent nanodrug (FND) by M-cells was investigated using a fluorescence microscope (Axio Imager 2; Carl Zeiss Meditec AG). The ethanol-treated glass slides were put in six-well plates and coated with $0.01 \%$ poly-L-lysine. The Caco-2 cells were seeded in these six-well plates at the density of $5 \times 10^{5}$ cells/well and allowed to adhere and grow. In one set of wells, Caco- 2 cells were co-cultured with Raji cells for 5-7 days to obtain M-cells, and other set of cells were kept as control. At the end of the incubation, cells were washed and supplemented with fresh media containing $0.07 \mathrm{mg} / \mathrm{mL}$ of nanodrug and incubated at $37^{\circ} \mathrm{C}$ for 2 hours. After the incubation, cells were washed with PBS to remove any unabsorbed free nanodrug. Fluorescence was measured in the lower (receiving) chamber from 0 hour to 48 hours in order to observe the FND transport via M-cells. For the fluorescence imaging studies, the cells were fixed with paraformaldehyde for 30 minutes and mounted on the slide and images of M-cells with accumulated FND were obtained as described above.

\section{Cellular toxicity of nanodrug}

Cytotoxicity of the nanoformulation was determined by using MTS assay (G3582; Promega Corporation) on Caco-2 cells and primary human macrophages. Briefly, cells were preincubated in 96-well plates with Caco-2 cells and then treated with various concentrations of nanodrug $(0.1-10 \mathrm{mg} / \mathrm{mL})$ for 24 hours at $37^{\circ} \mathrm{C}$. In case of primary human macrophages, cells were exposed at the concentrations of $1-100 \mu \mathrm{g} / \mathrm{mL}$ of nanodrug for 24 hours, separately. After the treatment, cells were washed and incubated with fresh respective growth medium. Cells were further incubated with $20 \mu \mathrm{L}$ of MTS reagent (CellTiter 96 ${ }^{\circledR}$ AQueous One Solution; Promega, Madison, WI, USA) in complete $100 \mu \mathrm{L}$ cell media for 1 hour at $37^{\circ} \mathrm{C}$. After the incubation, the absorbance at $490 \mathrm{~nm}$ was measured using the BioTek plate reader (BioTek). Untreated cells incubated with fresh media alone were considered as a control. All measurements were taken eight times. The net absorbance $(A)$ was taken as an index of cell viability. The cell viability was calculated as sample/control $\times 100 \%$. The nanoformulations that did not cause more than $10 \%$ loss in cell viability after at least 24 -hour exposure were considered nontoxic.

\section{Reactive oxygen species assay}

The productions of reactive oxygen species (ROS) following exposure to different concentrations of nanodrug (0.1-10 mg/mL) were detected in Caco-2 cells using dichlorofluorescein diacetate assay (Molecular Probes, Eugene, OR, USA) as per previous published protocol. ${ }^{22}$ Cells were cultured in 96-well plates $(100,000$ cells/well) overnight to allow $70 \%$ confluence. The next day, cells were treated with different concentrations of nanodrug for 24 hours as mentioned above. The following day, cells were washed and pretreated with antioxidant catalase $(0.001 \mathrm{mg})$ for 2 hours. Next, the cells were treated with dichlorofluorescein diacetate assay $(100 \mu \mathrm{M})$ for 1 hour at $37^{\circ} \mathrm{C}$ and finally read in a BioTek Synergy HT microplate reader (excitation $485 \mathrm{~nm}$ and emission $528 \mathrm{~nm}$; BioTek). Cells treated with $\mathrm{H}_{2} \mathrm{O}_{2}$ $(50 \mu \mathrm{M})$ for 2 hours were considered as positive control. ${ }^{22}$

\section{Anti-HIV activity of nanodrug}

The nanodrug was further investigated for anti-HIV activity in primary human macrophage and M-cell culture model, respectively.

Primarily, human peripheral blood mononuclear cells were isolated from healthy donor and differentiated to macrophages as per previously published protocol. ${ }^{23}$ Briefly, peripheral blood mononuclear cells were isolated with Ficoll-Hypaque (Pharmacia) gradient and cells were allowed to differentiate for 7 days in the presence of human macrophage colony stimulating factor (Sigma-Aldrich Co.) to macrophages. Following 7 days of incubation, macrophages were infected with HIV-1BaL (National Institutes of Health AIDS Research and Reference Reagent Program; Cat 510) (100 ng) and incubated for 24 hours. The next day, cells were thoroughly washed to get rid of any unattached virus particle and fresh medium was added. At the same time, same concentration $(70 \mu \mathrm{g} / \mathrm{mL})$ of nanodrug and unformulated drug (EFV) was added to these cells separately. The HIV-infected macrophages served as control. The nanodrug/EFV drugtreated cells were monitored for up to 10 days along with 
infected control cells. The cell supernatant was collected at days $0,1,3,5$, and 7 and 10 days post treatment. The viral p24 level in the supernatant was measured with p24 ELISA assay (Cat 0801200; ZeptoMetrix Corporation, Buffalo, NY, USA). The minimum assay detection limit for p24 antigen by ELISA was $7.8 \mathrm{pg} / \mathrm{mL}$ as provided by the manufacturer. The p24 level at different time points gave the level of viral inhibition with nanodrug and EFV. The p24 level of the culture supernatant was inversely proportional to the anti-HIV activity of nanodrug.

Simultaneously, a parallel anti-HIV activity study was set up in an in vitro model of M-cell. In this model, Raji cells were exposed to HIV-1BaL at the concentration of $100 \mathrm{ng}$ for 24 hours in a co-culture and then washed from unattached viral particles. ${ }^{24,25}$ Following this, same concentration $(70 \mu \mathrm{g} / \mathrm{mL})$ of nanodrug and EFV was added to M-cell culture model separately. The M-cell co-culture model was observed for 10 days for viral replication, which was measured by p24 ELISA assay (ZeptoMetrix Corporation) at different time points up to 10 days. The untreated Raji cells were kept as a control for all the experiments related to drug activity. In the M-cell culture model, infected Raji cells were also treated with EFV to compare with nanodrug. The effect of nanodrug on HIV replication was measured for up to 10 days post treatment in culture supernatant.

At the end of both the experiments, a quantitative HIV-1 DNA protocol (long terminal repeat [LTR] real-time polymerase chain reaction) was used to analyze the viral transcripts in HIV-infected Raji cells and macrophages. This was done in order to ensure that untreated macrophages and Raji cells got infected with the exposure of HIV-1. The following previously published ${ }^{23}$ primers and probes were used: LTR U5/R - sense-5'-GGCTAACTAGGGAACCCACTG-3', antisense-5'-CTGCTAGAGATTTTCCACACTGAC-3', and probe $5^{\prime}$-FAM-TGTGTGCCCGTCTGTTGTGTGTAMRA-3'. Relative gene expression was quantitated, and the mean fold change in expression of the target gene was calculated using the comparative CT method (transcript accumulation index $=2-\Delta \Delta \mathrm{CT})$. All data were normalized for quantity of RNA input by performing measurements on an endogenous reference gene, GAPDH.

\section{Statistical analysis}

All experiments were performed in replicates, and data are presented as mean $\pm \mathrm{SE}$. The statistical analysis was done by two-tailed paired $t$-test with GraphPad Prism software (GraphPad Software, Inc., La Jolla, CA, USA). A $P$-value of $\leq 0.05$ was considered as significant.

\section{Results and discussion Preparation and characterization of nanodrug formulation}

EFV is a non-nucleoside reverse transcriptase inhibitor being used as part of HAART for the treatment of HIV-1 infection. Although it is always given in combination with other drugs to treat HIV infection, low efficacy is still a main concern for this drug. This is due to its poor aqueous solubility, low bioavailability, and resistance profile that may attenuate its therapeutic effect. ${ }^{26}$

Currently, nanotechnology has attracted significant attentions in the field and also brought a revolutionary change in the drug delivery system. By now, over 20 nanodrug formulations have been approved by US Food and Drug Administration (FDA). ${ }^{27}$ Among these nanomaterials, F127 plays an important role because of its specific chemical structure and excellent biological biocompatible future. ${ }^{17}$ Figure $1 \mathrm{~A}$ and $\mathrm{B}$ elucidated the main idea for the preparation of F127COOH-EFV nanodrug formulation. The synthetic yield of F127COOH from F127 was around 85\%. The load yield of EFV in F127COOH-EFV nanodrug formulation, close to $100 \%$, was determined by HPLC assay.

As shown in Figure 1A, Pluronics are block copolymers that consist of hydrophilic polyethylene oxide (PEO) and hydrophobic polypropylene oxide (PPO) blocks arranged in a basic PEO $x$-PPOy-PEO $x$ structure (where $x$ and $y$ represent the repeated number of times ethylene oxide [EO] and propylene oxide [PO] in the structure, respectively). F127 can easily form as core/shell nanoparticles in the aqueous solution by simple hydration technique, and its hydrophobic core can act as an accommodation for lipophilic drug. In this spontaneously formed core-shell structure, poorly soluble drugs can be incorporated into the hydrophobic core and protected from inactivation in biological media, and the outside, hydrophilic section layer may endow the micellar system many advantages, such as increased drug solubility, circumvented reticuloendothelial system uptake, improved circulation time, and enhanced permeability and retention effect. ${ }^{3}$ It has already been applied in the fields of biomedicine, drug delivery systems, and gene therapy due to its amphiphilic structure and high biocompatibility. ${ }^{28,29} \mathrm{~F} 127$ Pluronic $\left(\mathrm{PEO}_{101}-\mathrm{PPO}_{56}-\mathrm{PEO}_{101}\right)(\mathrm{SP} 1049 \mathrm{C})$ is now tested in Phase III clinical investigation in patients with metastatic adenocarcinoma of the esophagus, gastroesophageal junction, and stomach. It has been reported to exhibit an acceptable safety profile with a maximum tolerated dose of $70 \mathrm{mg} / \mathrm{m}^{2}$ with sustained drug release and clearance profile in comparison to conventional formulation. ${ }^{30,31}$ 
To improve the target efficiency, new type of F127 with functional group is produced by surface chemical structure modification. In our study, carboxyl groups were introduced on the PEO terminal of F127 (the product of carboxylated $\mathrm{F} 127$ is abbreviated as $\mathrm{F} 127 \mathrm{COOH}$ ) for the purpose of bioconjugation via gentle esterification with maleic anhydride. By typical preparation process of micelles, EFV encapsulated in carboxyl-functionalized amphiphilic polymers can result in stable, micelle-like structures due to the strong hydrophobic interactions between native hydrophobic EFV and the PPO hydrocarbon chains (from hydrophobic section of F127) to form F127COOH-EFV nanoparticles. Anti-GP2 antibodies were conjugated with carboxyl groups on the surface of F127 via the formation of active amino intermediate group (Figure 1B). Being a very specific monoclonal antibody designed for human M-cells, anti-GP2 antibody will help in specific targeting of this nanodrug toward M-cell located at the GALT. 32,33

This work is a consequent study based on our previous achievement on the $\mathrm{F} 127 \mathrm{COOH}$ application. ${ }^{17}$ As we reported before, the degree of maleic acid substitution onto F127 was $\sim 1.5 \mathrm{~mol} \%$. The yield of $\mathrm{F} 127 \mathrm{COOH}$ in this synthesis was measured to be above $85 \%$ by acid-base titration, and no significant degradation of the copolymer was found. The CMC determined the stability of micelles against possible dilution of the micellar system in bodily fluids. To this end, the $\mathrm{CMC}$ of $\mathrm{F} 127 \mathrm{COOH}$ nanoparticles was $4.7 \times 10^{-7} \mathrm{M}$, which indicates extreme stability after dilution. The size of F127COOH-EFV nanodrug formulation in aqueous media was around $140 \mathrm{~nm}$ with excellent monodispersion under TEM measurement, shown in Figure 2A. The hydrodynamic size in aqueous dispersion by method of DLS has high consistence with TEM results, which was around $140 \mathrm{~nm}$ with
0.12 polydispersion index (PDI). In general, the value of PDI less than 0.3 is recognized as a narrow size distribution for particles. The shape and the size were not significantly altered after conjugation with anti-GP2 antibodies. The TEM analysis clearly indicated that no aggregation occurred during the conjugation process. The surface charge of F127COOH-EFV nanodrug formulation was $19.38 \pm 2.2 \mathrm{mV}$ by zeta potential measurement. Vectorization of the nanocarriers with antibodies did not affect the surface charge and had negligible change in the particles.

DLS technique was also used to measure the hydrodynamic size distribution and colloidal stability of F127COOHEFV in PBS. As displayed in Figure 2B, the DLS results showed the average hydrodynamic radius of $\mathrm{F} 127 \mathrm{COOH}-$ EFV to be $128.8 \pm 15.6 \mathrm{~nm}$ (PDI $=0.10$ ) over 2 weeks. The surface charges of nanodrug formulation of $\mathrm{F} 127 \mathrm{COOH}-\mathrm{EFV}$ were not significantly changed with or without conjugation of antibodies based on the DLS measurements. The mimic stability evaluation in blood fluid was also found to be stable by measuring their size in an in vitro closed circulatory system at $37^{\circ} \mathrm{C}$ for up to 28 hours (viscosity: $4.5 \mathrm{cP}$ )..$^{19}$ The time-dependent changes in hydrodynamic diameter of the F127COOH-EFV with conjugation of antibodies were less than $10 \%$ under the PBS (pH 7.4) and $0.005 \%$ pepsin solution ( $\mathrm{pH} \mathrm{6.8)} \mathrm{(Figure} \mathrm{3A} \mathrm{and} \mathrm{B),} \mathrm{indicating} \mathrm{that} \mathrm{these}$ nanoparticles have well colloidal stability for a quite long term in a blood physiological condition and intestine enzymatic circumstance.

Generally, the stability test on nanodrug under gut circumstance is critical for the full understanding of the characterization and fate of particles applied in in vivo model and potential clinic. In our strategy, this nanodrug will be finally encapsulated into an enteric-coated capsule for oral

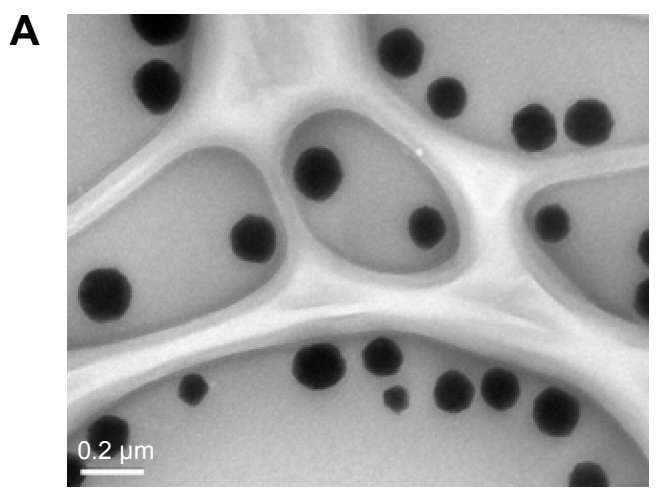

B

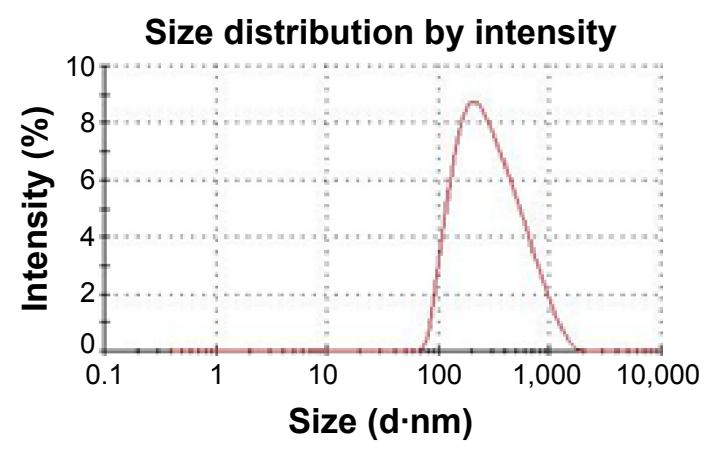

Figure 2 (A) TEM and (B) DLS of the formulation.

Notes: (A) Presents the representative particle shape and size of FI27COOH-EFV nanodrug around I20-I40 nm using the TEM technique, which shows excellent monodispersion directly. (B) Displays the hydrodynamic radius of $\mathrm{FI} 27 \mathrm{COOH}-\mathrm{EFV}$ nanodrug particles in the aqueous solution about I30 nm using the DLS technique with small size distribution index (PDI) as 0.10 . The hydrodynamic size in aqueous dispersion by the method of DLS has high consistency with the TEM results.

Abbreviations: DLS, dynamic laser scattering; EFV, efavirenz; PDI, polydispersion index; TEM, transmission electron microscopy. 
A

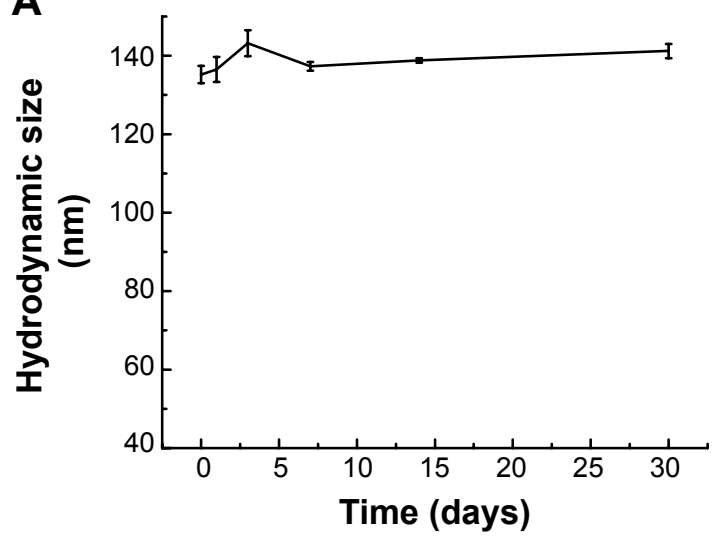

B

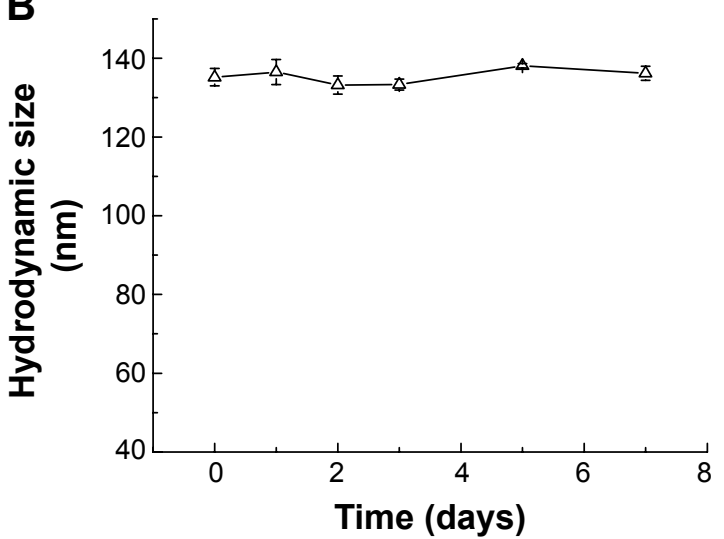

Figure 3 Stability characterization of nanoformulation: (A) pH 7.4 PBS and (B) $0.005 \%$ pepsin solution.

Notes: (A) DLS hydrodynamic size against time indicated the long-term stability of nanodrug in aqueous solution. Both of them showed size fluctuation $<10 \%$. Hydrodynamic diameter of FI27COOH-EFV presented size fluctuation $<10 \%$, indicating the long-term well colloidal stability in a physiological condition ( $\mathrm{pH} 7.4$ ). (B) One week incubation with $0.005 \%$ pepsin solution showed the stability of nanoformulation under intestine enzymatic circumstance.

Abbreviations: DLS, dynamic laser scattering; EFV, efavirenz; PBS, phosphate-buffered saline.

administration in animals. This enteric surface coatings can endow capsule presenting stability at highly acidic $\mathrm{pH}$ (eg, in stomach) and breaks down rapidly at around $\mathrm{pH} 6.8$ (eg, in intestine) to release drug. This is the main reason why the stability test and drug release measurement are not conducted under acidic condition in our experiment for nanodrug.

In order to find out hydrodynamic size variation of F127COOH-EFV nanodrug under mimetic intestine solution (0.005\% pepsin solution, $\mathrm{pH} 6.8$ ), DLS size of particles was monitored against time up to 7 days. The results showed that fluctuation in diameter of particles was less than $10 \%$ in 7 days, which is almost same as the variation extent in water (Figure 3B). This 1-week measurement confirmed the stability of nanoformulation under intestine enzymatic circumstance.

Since drug release from nanoformulation follows diffusion mechanism, with intact shape and structure under intestine enzymatic circumstance, the loaded EFV may release at the targeted site and time once the nanoformulation is encapsulated into enteric-coated capsule and administered into mice. All these parameters, including drug pharmacokinetic and distribution, will be performed in future in vivo studies.

\section{Sustained drug release of nanodrug}

To analyze the drug release profile, F127COOH-EFV was subjected to dissolution test. In complying with sink condition from FDA requirement on drug product dissolution, F127COOH-EFV in PBS (pH 7.4) was placed in the dialysis bag using composition of $0.1 \%$ Tween 20 aqueous solution as dissolution solution at $37^{\circ} \mathrm{C} .{ }^{34}$ The released drug outside of dialysis bag was sampled at different time intervals (from 5 minutes up to 14 days) and was assayed by HPLC. ${ }^{35}$

The data indicated that $80 \%$ of drug was released from the Pluronic particles over 6 days. As shown in Figure 4, the $t_{1 / 2}$ of EFV in F127COOH-EFV nanodrug formulation was about 48 hours $\left(t_{1 / 2}=48\right.$ hours). This was considerably longer than the release of free drug $\left(t_{1 / 2}=8\right.$ hours $)$. This phenomenon presents the acceptable characterization for sustained drug release in in vitro and may satisfy work in in vivo. The free EFV without dialysis bag was also used as second control, which provided $t_{1 / 2}=0$ hour under the same

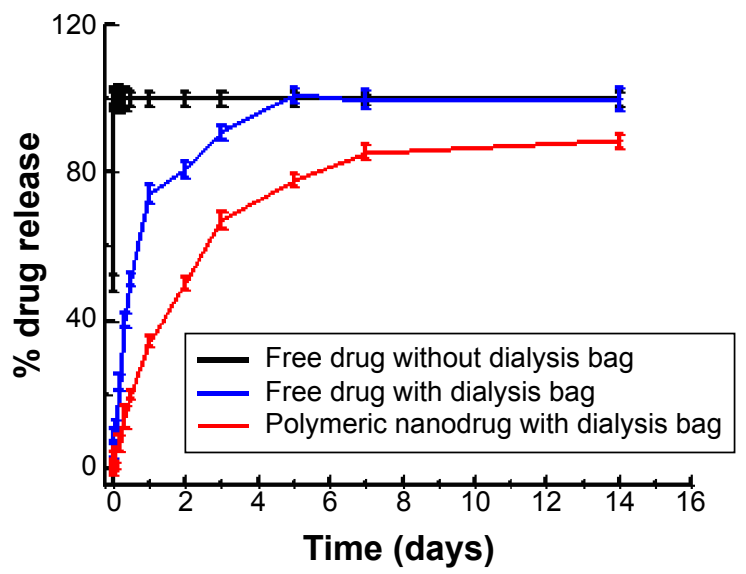

Figure 4 Dissolution study of nanodrug in PBS in in vitro model. Notes: Dispersion of the micelles in PBS ( $\mathrm{pH}$ 7.4) placed in the dialysis bag and dialyzed against the respective buffer solution at $37^{\circ} \mathrm{C}$. The released drug outside of dialysis bag was sampled at different time intervals (from 5 minutes up to 14 days) and measured by HPLC. The data were expressed as $80 \%$ of drug released from the Pluronics relative to the initial drug loading.

Abbreviations: HPLC, high-performance liquid chromatography; PBS, phosphatebuffered saline. 
dissolution condition. The delayed release of free drugs in dialysis bag may come from the retardation effect of tight composition in the cellulose structure. ${ }^{35}$ In vitro release of drug from polymeric micelles was measured by the dialysis bag diffusion technique. ${ }^{36}$ According to US pharmacopeia, phosphate buffer ( $\mathrm{pH} 7.4$ ) containing $0.5 \%$ Tween 80 was used as a dissolution medium. This dialysis-based in vitro release assays under sink condition have been commonly applied to assess the retention properties of encapsulated drugs. However, these results are not always indicative of the formulations' actual in vivo behavior. There are two mechanisms for the drug release delay: one is caused by sustained drug release from the reservoir effect in polymeric vehicles, which may attenuate with time and another retention effect may come from the dialysis bag itself. It is reported that the dialysis bag may limit the in vitro drug release. ${ }^{37}$ Although there is a drug release delay and about $15 \%$ of drug remained in the dialysis bag from this in vitro method, this dose decrease will not affect the administrated drug for the future in vitro and in vivo application. Even considering this delay impact from dialysis bag, the dissolution profile for our Pluronic nanodrug formulation is still adequate for sustained drug release requirement.

\section{Cytotoxicity of nanodrug}

The present study investigated a potential of nanodrug as the M-cell-specific drug delivery vehicle for the GALT. Lymphatic uptake of nanoparticle, retention, and sustained release of the drug at the GALT depend mainly on the size, shape, and surface characterization of the nanoparticle. Generally, smaller particles have better lymphatic uptake than larger particles with lower retention capability. ${ }^{2,38-40}$
In this regard, steric stabilization with hydrophilic polymer like F127COOH can improve the uptake of EFV by lymph nodes and increase their stabilization inside them. Lymph node retention of micellar drug has been investigated by other researchers in cancer therapy. ${ }^{41}$ However, it had limited success due to poor loading capacity and toxicity issue. ${ }^{42}$ In order to address this issue, we carried out cytotoxicity studies of this nanodrug (Figure 5).

In this regard, MTS assay was performed to evaluate the cytotoxicity of nanodrug in Caco-2 cells and primary human macrophages, respectively, as per published protocol. ${ }^{43}$ The result indicated that nanodrug did not significantly affect the cell viability over 24 hours incubation with Caco- 2 cells at nanodrug concentration of $0.1-10 \mathrm{mg} / \mathrm{mL}$ (Figure $5 \mathrm{~A}$ ). Even in case of primary human macrophage, the effect of nanodrug on cell viability did not decrease significantly up to the concentration of $100 \mu \mathrm{g} / \mathrm{mL}$ (Figure 5B). Both observations indicated that there was no immediate cellular toxicity of nanodrug on human cell line (Caco-2) and primary human cells (macrophages) at the tested concentrations. Taking into account the high drug-loading capacity and cellular toxicity, high drug concentrations (above $10 \mathrm{mg} / \mathrm{mL}$ ) were not considered for further evaluations. Along the same line, the ratio of drug and polymer was also optimized in Caco- 2 and Raji cells in order to get the maximum drug activity (data not shown). As a result, $0.07 \mathrm{mg} / \mathrm{mL}$ of nanodrug was used for further in vitro characterization.

\section{Effect of nanodrug on ROS production in Caco-2 cells}

It was also important to test whether the current nanodrug itself causes oxidative stress to the cellular environment after
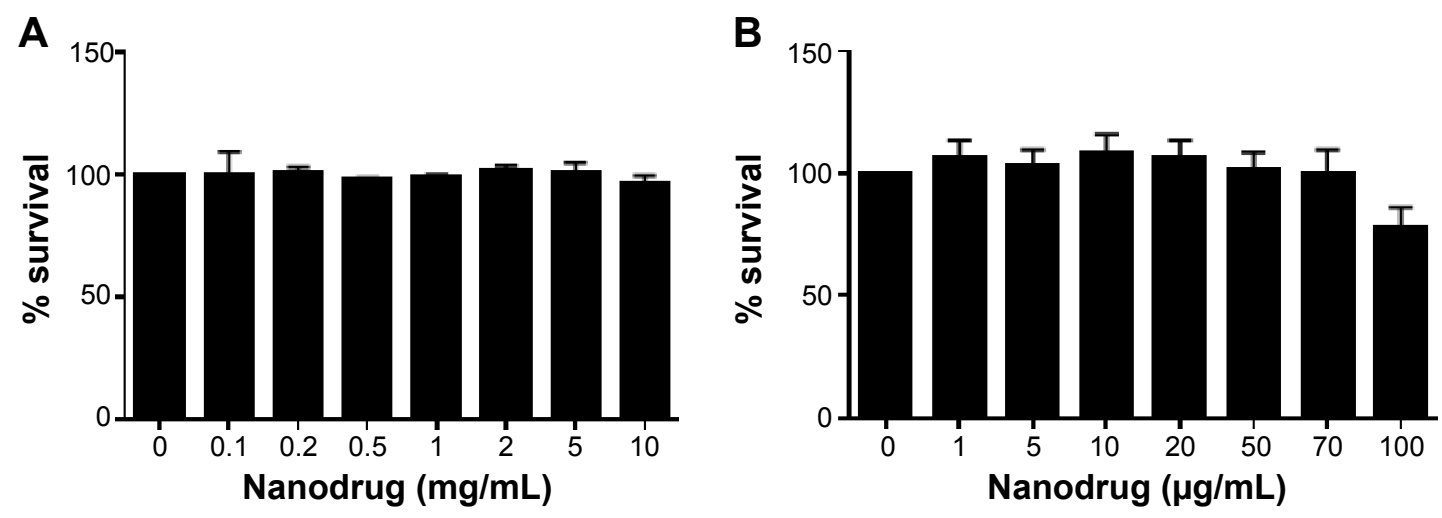

Figure 5 Cytotoxicity of nanodrug on Caco-2 cells and primary human macrophages.

Notes: (A) Caco- 2 cells were exposed to $0.1-10 \mathrm{mg} / \mathrm{mL}$ concentration of nanodrug for 24 hours. (B) Primary human macrophages were exposed to $1-100 \mu g / \mathrm{mL}$ concentration of nanodrug for 24 hours. After incubation, MTS assay was performed and optical density of culture supernatant was measured at 490 nm. Data were presented as \% survival of cells at different concentrations of nanodrug. Untreated cells were considered as control $(0)$ with $100 \%$ viability. The changes in viability at different concentrations of nanodrug compared to control were found to be nonsignificant.

Abbreviation: MTS, 3-(4,5-dimethylthiazol-2-yl)-5-(3-carboxymethoxyphenyl)-2-(4-sulfophenyl)-2H-tetrazolium. 
treatment, which may affect cellular metabolism. In this regard, cells were treated with different concentrations of nanodrug in order to observe the effect of this formulation on ROS production. As explained in Figure 6, the current nanodrug did not induce any significant ROS production with the treatment as high as $10 \mathrm{mg} / \mathrm{mL}$. This observation indicated that the current formulation did not cause any oxidative stress to Caco-2 cells post treatment. Thus, it further assured the nontoxicity of the nanodrug for cellular treatment.

\section{Characterization of M-cells in co-culture model}

In the co-culture model, Caco- 2 cells developed M-cellslike morphology after incubation with Raji cells. In order to investigate the transformation of Caco- 2 cells to M-cells, a flow-cytometry analysis was done with M-cell-specific antiGP2 antibodies. ${ }^{44,45}$ Monoculture of Caco-2 cells was used for this study as a negative control. The data indicated that $14 \%$ of the Caco-2 cells developed M-cells-like characteristics upon co-culturing with Raji cells (Figure 7), whereas there was no M-cell characters observed in monoculture of Caco-2 cells. Thus, the transformations of M-cells from Caco- 2 cells were clearly observed through this analysis.

In order to confirm this observation, further characterization of M-cells was done through immunocytochemistry with anti-GP2 antibodies. The cells were grown and co-cultured

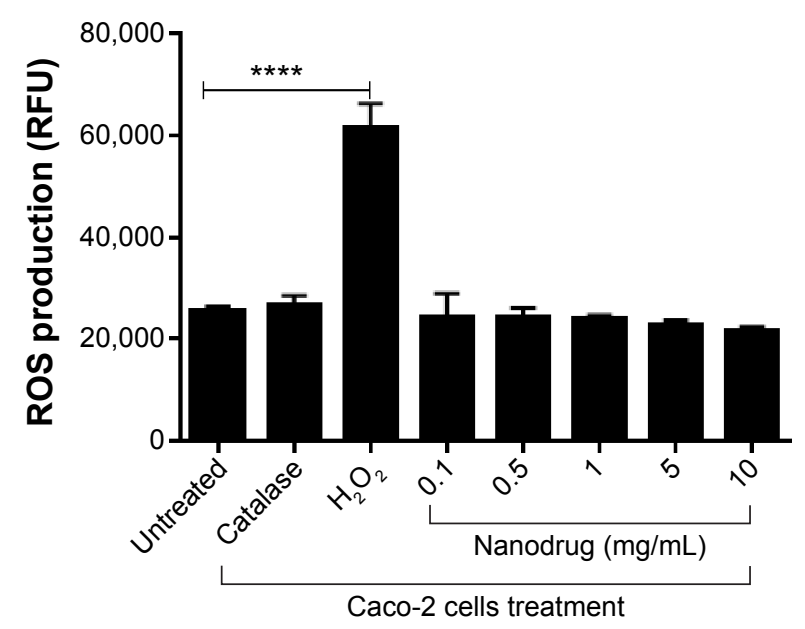

Figure 6 Effect of nanodrug on ROS production in Caco-2 cells.

Notes: Cells were exposed to $0.1-10 \mathrm{mg} / \mathrm{mL}$ concentration of nanodrug for 24 hours. At the end of incubation, ROS assay was performed. The fluorescence was detected at $485 \mathrm{~nm}$ excitation and at $528 \mathrm{~nm}$ emission spectra. Catalase was used as antioxidant control, and $\mathrm{H}_{2} \mathrm{O}_{2}$ was used as positive control. Data are expressed as mean \pm SE of RFU values of four independent experiments. A value of $P<0.000$ I was indicative of significance $(* * * *)$. There was no statistical significance between treated groups and control.

Abbreviations: ROS, reactive oxygen species; RFU, relative fluorescence unit; SE, standard error. as mentioned above, and at the end of incubation, cells were stained with anti-GP2 antibodies. The fluorescent image analysis indicated that the presence of anti-GP2 antibodies was significantly higher in M-cells compared to Caco-2 cells alone as explained in Figure 8.

\section{Assessment of model functionality by FND transport}

In order to monitor the functional activity of M-cell in in vitro model, a transport study of Alexa Fluor 610X NHS esterconjugated nanodrug or FND was designed and monitored the transport rate in mono (Caco-2) and co-culture (M-Cell) models. These FND formulations were further conjugated with anti-GP2 antibodies (FND-GP2). FND and FND-GP2 were added apically and incubated for 2 hours at $37^{\circ} \mathrm{C}$. After the incubation, parts of the Transwells were used for fluorescent microscopy studies to observe FND accumulation and a parallel set of Transwells was kept to monitor the FND transport from apical to basolateral site. The microscopic analysis indicated that FND-GP2 was more accumulated in the M-cells, at a greater extent, than FND. At the same time, the Caco- 2 cells treated with FND and FND-GP2 accumulated significantly less fluorescence than the M-cells (Figure 9A).

Noteworthy, both M-cells and Caco-2 cells showed a sustained uptake of FND in the external medium. The measurement of FND uptake on the basolateral side of Transwell was done by measuring fluorescence. The nanodrug uptake was measured in terms of fluorescence with respect to time up to 48 hours. Along with higher accumulation levels, the prolonged drug release characteristics from M-cells were demonstrated compared to Caco- 2 cells, indicating the superior role of M-cells for drug delivery (Figure 9B). We hypothesized that Pluronic micelles were transported out of the cells through recycling trafficking of endosomes as reported previously. ${ }^{46}$

\section{Anti-HIV activity of nanodrug}

Anti-HIV activity of nanodrug against HIV was tested in primary human macrophages and in vitro M-cell model. Primarily, human macrophages were infected with HIV-1 for 24 hours and then treated with nanodrug or EFV separately. Nanodrug treatment data indicated that there was consistent viral inhibition up to day 10 and beyond, whereas free EFVtreated cells showed immediate inhibition of viral replication on day 1 and following that there was an increase in viral p24 level, indicating gradual loss in antiviral activity of EFV. At the end of the experiment (day 10), the effect of EFV 

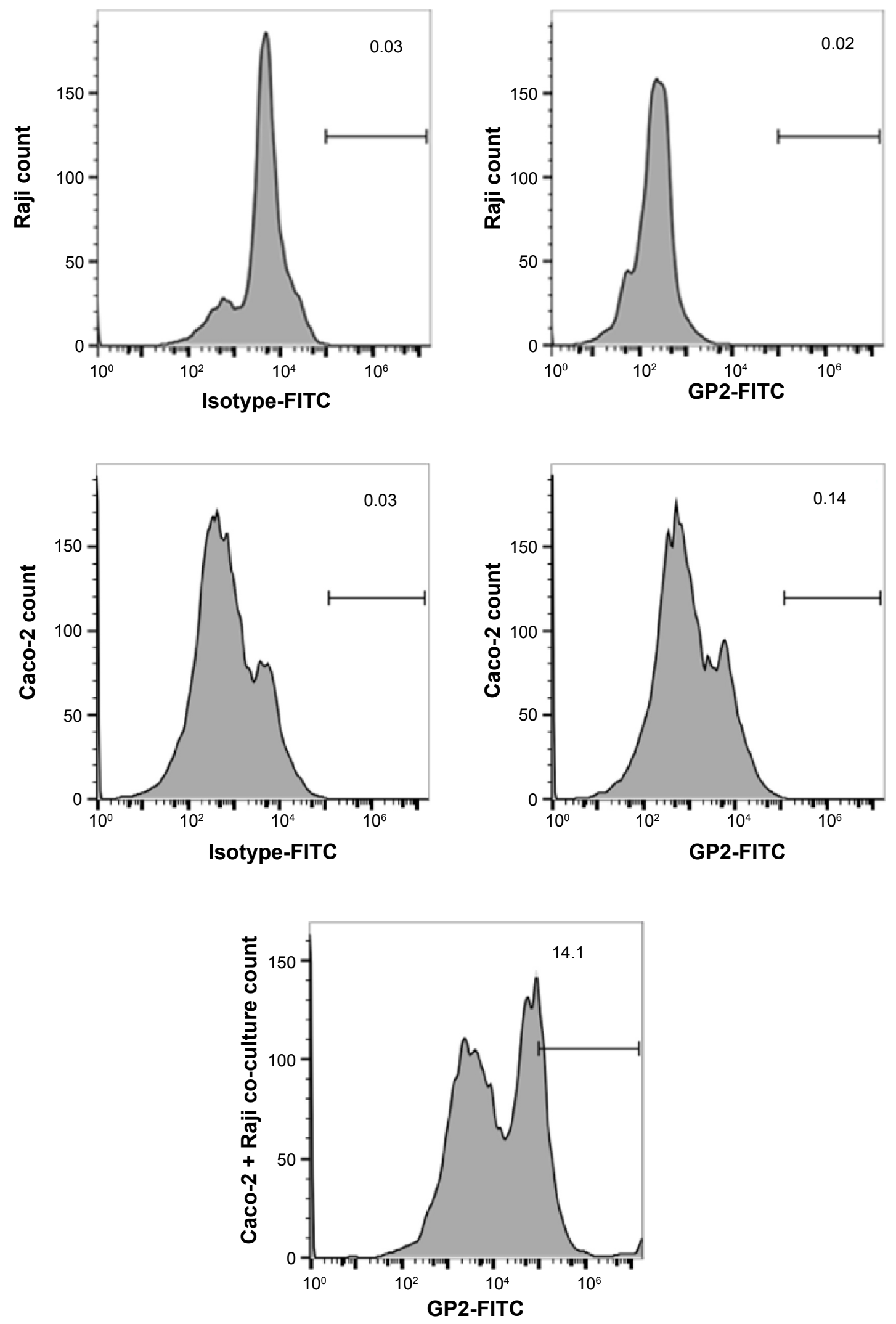

Figure 7 Flow cytometric analysis of M-cell-like characteristics in Caco-2 and Raji cell co-culture systems.

Notes: Caco-2, Raji, and Caco-2 + Raji cells were cultured simultaneously and stained with anti-GP2 antibody at the end of incubation. Cells were gated for GP2, based on the isotype in the respective cells.

Abbreviations: FITC, fluorescein isothiocyanate; GP2, glycoprotein 2. 

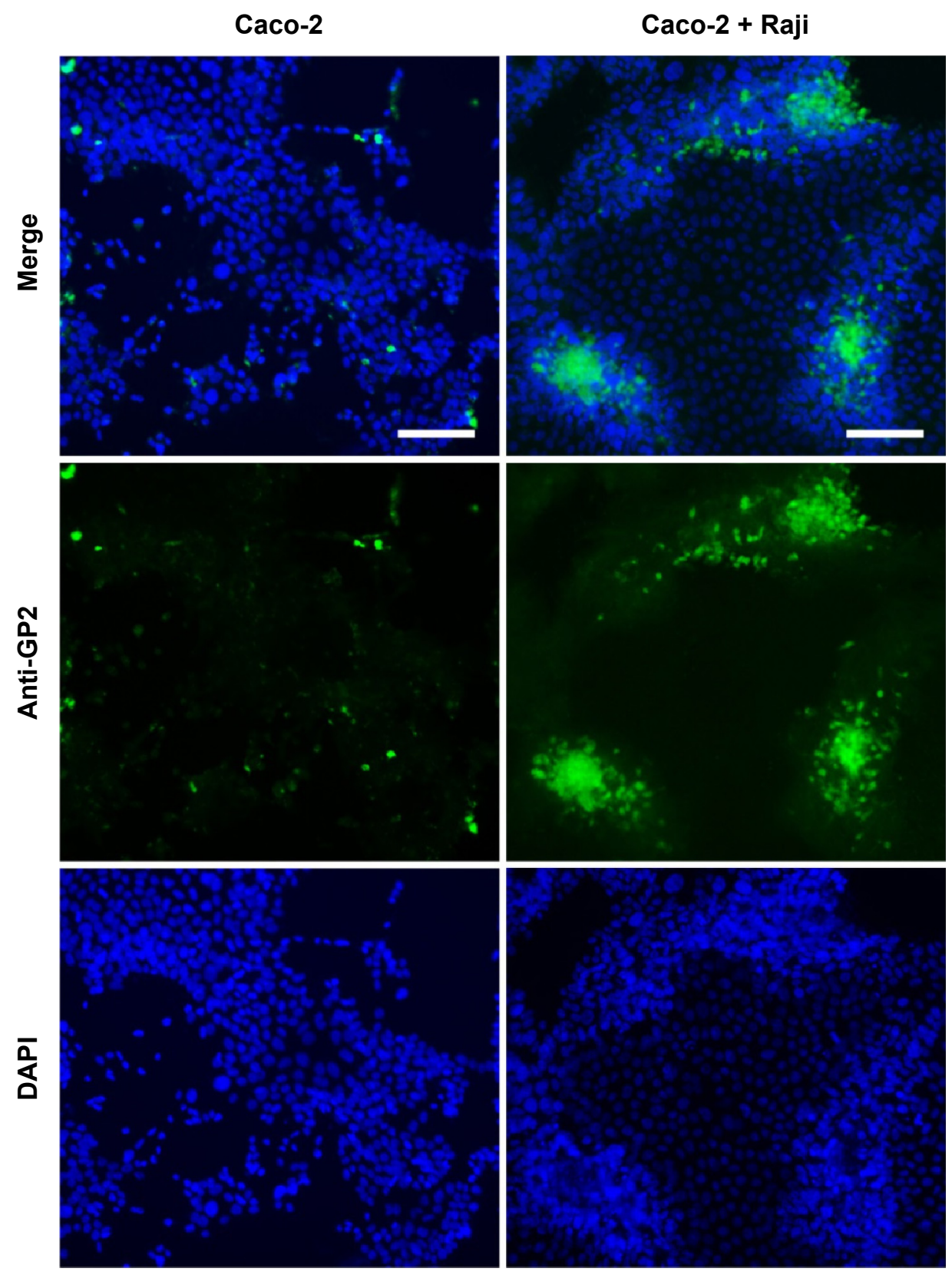

Figure 8 Immunocytochemical analysis of M-cell characters in Caco-2 and Raji co-culture.

Notes: Cells were exposed to anti-GP2 antibody after differentiation process and stained with fluorescent secondary antibody. Microscopic images were taken through Axio Imager 2. DAPI (in blue) indicated the cell nucleus, and the cells those have developed M-cell-like characteristics were stained with GP2 antibody (green).

Abbreviations: DAPI, 4',6-diamidino-2-phenylindole; GP2, glycoprotein 2.

treatment significantly decreased and p24 level increased up to the level of untreated cells. In this regard, untreated and HIV-1-infected macrophages were served as a positive control, which showed gradual increase in the p24 level up to day 10 , indicating unaffected HIV-1 replication in macrophages (Figure 10A).

In order to observe anti-HIV activity of nanodrug in M-cell model, Raji cells were infected with HIV and cultured with Caco-2 cells. They were further treated separately with nanodrug or EFV for up to 10 days at the same concentration.
Viral p24 protein level was measured in culture supernatant at different time points. In the case of nanodrug, p24 protein level did not change up to day 2. However, from day 3 to day 10 , there was a significant decrease in viral replication when compared to EFV-treated cells. Compared to nanodrug, EFV treatment resulted in an immediate reduction in viral replication, but p24 level increased closer to the level of untreated cells within day 10 , indicating viral rebound in the cells (Figure 10B). As a positive control, p24 level of HIV-infected Raji cells was observed up to day 10. 

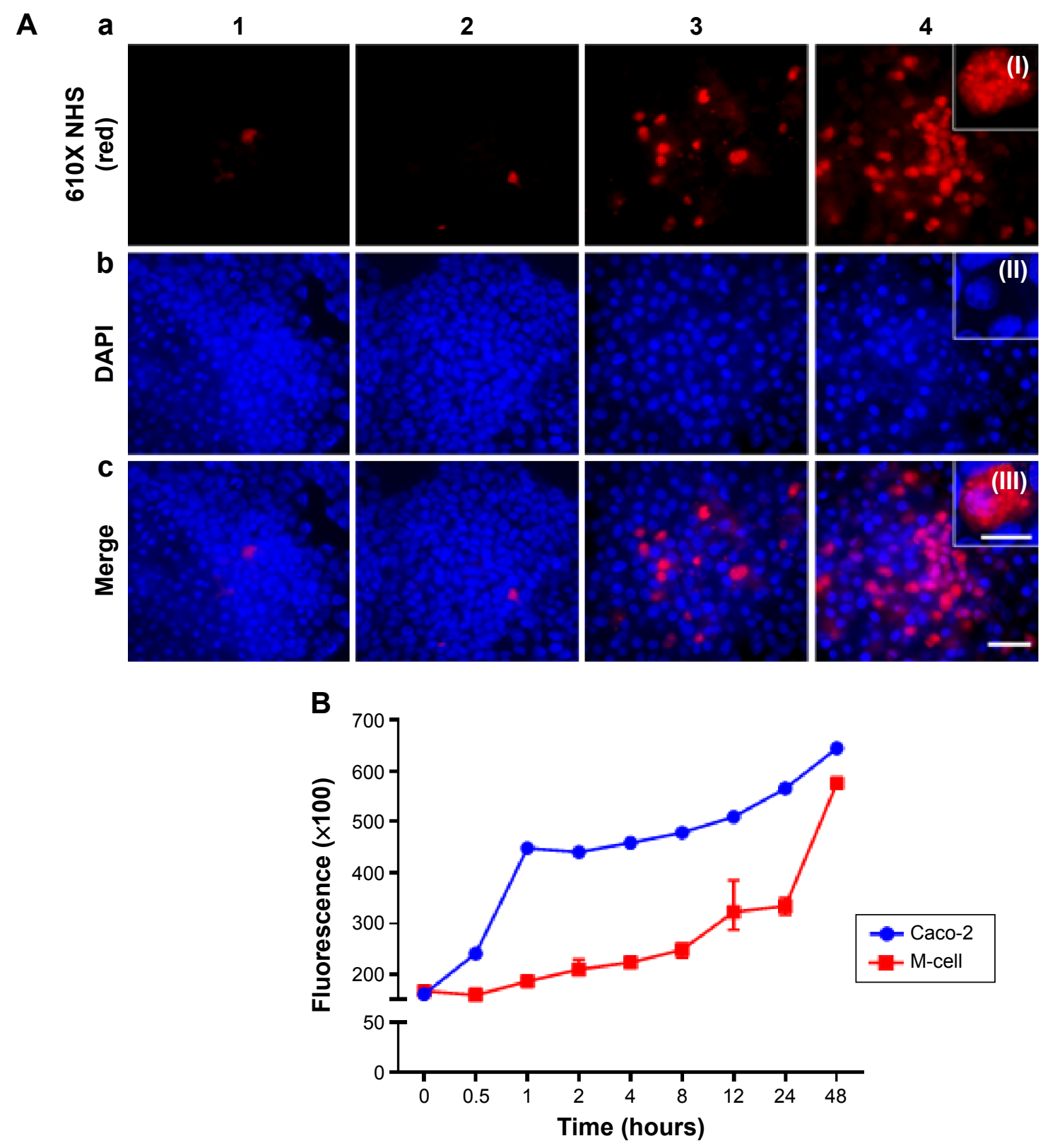

Figure 9 Uptake and release of fluorescent dye (Alexa Fluor 610X NHS ester) labeled nanodrug (FND) by M-cells.

Notes: (A) Uptake of anti-GP2-conjugated nanodrug by M-cells within 2 hours of incubation. Caco-2 and M-cells were treated with and without antibody (GP2) tagged with FND. The treatments were as follows (from left to right): (I) Caco-2 cells treated with FND; (2) Caco-2 cells treated with FND + GP2; (3) M-cells treated with only FND; and (4) M-cells treated with FND + GP2. Cells were stained with DAPI in order to observe the localization of FND and are represented in the following order: (a) FND; (b) DAPI; and (c) FND and DAPI merged (scale bar $50 \mu \mathrm{m}$ ). Co-localization of FND on the cell surface is shown as a magnified image in (I), (II), and (III) of A (scale bar $=20 \mu \mathrm{m}$ ). (B) Release of FND in vitro Transwell co-culture model at lower chamber. Drug release was observed with respect to fluorescence measurement. Fluorescent drug release was significantly sustained in $M$-cells than Caco-2 cells $(P<0.0015)$.

Abbreviations: DAPI, 4',6-diamidino-2-phenylindole; FND, fluorescent nanodrug; GP2, glycoprotein 2; NHS, N-hydroxysuccinimide.

At the end of two experiments, the primary infection of HIV-1BaL in both Raji and macrophages was confirmed by HIV-LTR-R/U5 gene polymerase chain reaction. The data represented in transcript accumulation index values in both cells indicated that both cell types were successfully infected with HIV and presented an optimum challenge to test the nanodrug in evaluating its anti-HIV activity (Figure 10C).
The epithelium layer that lies in the gut is impermeable to any macromolecules, including drug molecules except Peyer's patches that contain M-cells. ${ }^{11,13}$ In this study, we have adopted an in vitro culture system that reproduced the characteristic of M-cells. Since this in vitro model is the only tool to study the human M-cells, it was very important to characterize it in detail. The biological characterization revealed that the presence of Raji cells in co-culture with 
A

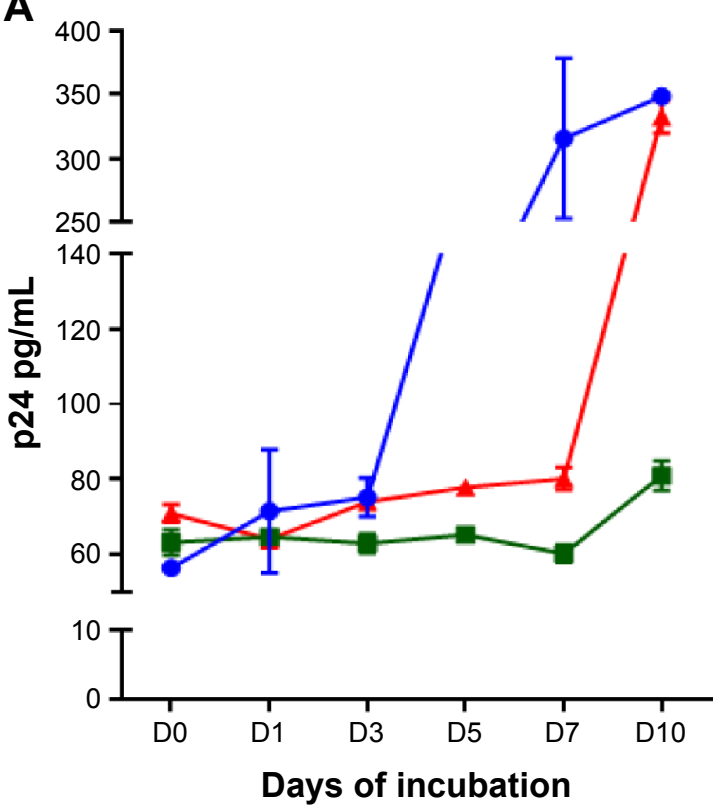

B

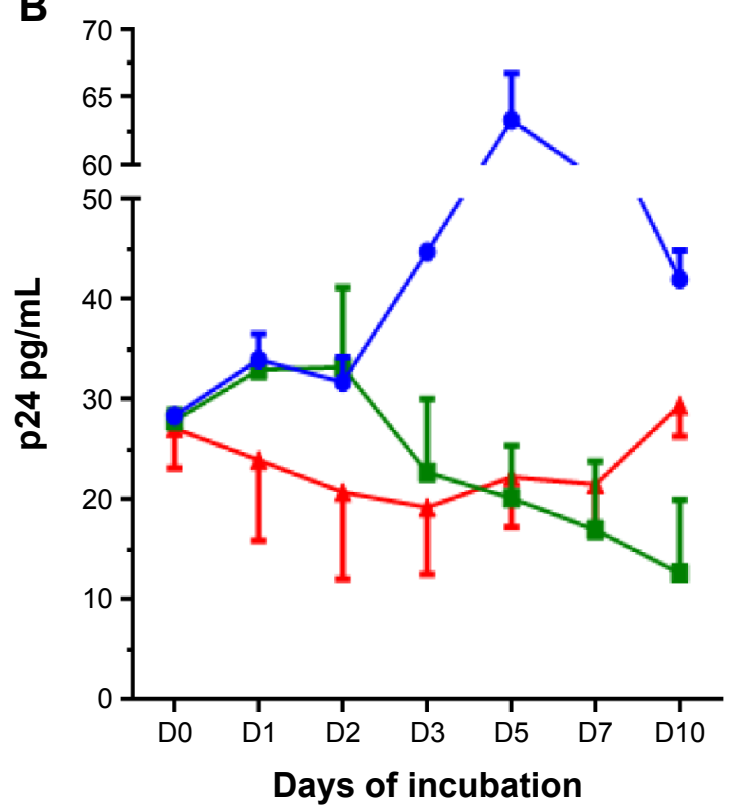

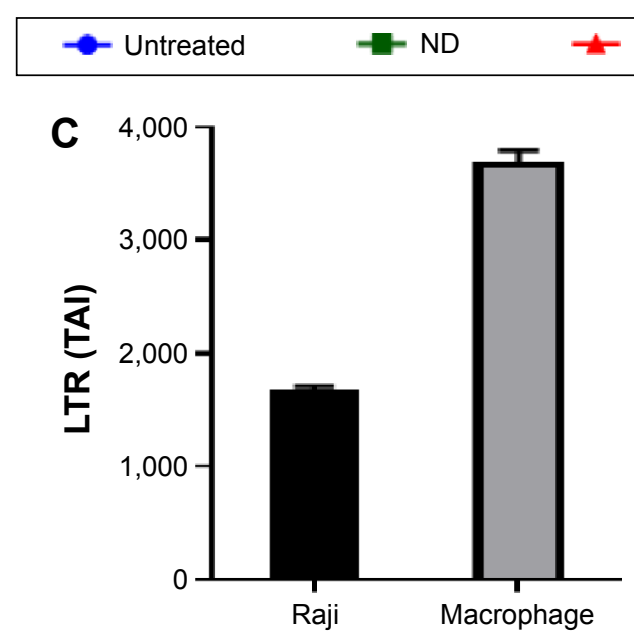

HIV-1 infected cells

Figure 10 Comparative analysis of anti-HIV activity of nanodrug vs unformulated EFV on macrophages and M-cells.

Notes: (A) Effect of nanodrug on HIV-infected macrophages compared to EFV. (B) Effect of nanodrug or EFV was observed on HIV replication in M-cell culture model. HIV replication was monitored with respect to p24 protein level in the culture supernatant at different times (days). The data represented with respect to p24 level vs time (days) in untreated, nanodrug-treated (ND, in green), and EFV drug-treated (FD, in red) M-cells exposed to HIV ( $P=0.00 \mathrm{I})$. Untreated and HIV-infected macrophage/Raji cells were treated as positive control (in blue). Statistical significance was calculated with respect to $P$-values $(P=0.00 \mathrm{I})$. (C) HIV-LTR-R/U5 gene expression was done through PCR. The two columns show HIV infection in the Raji (black) and macrophage (gray) cells after 10 days of incubation. The LTR gene expressions in both cells were expressed in TAI and normalized with housekeeping gene GAPDH.

Abbreviations: D, day; EFV, efavirenz; HIV, human immunodeficiency virus; LTR, long terminal repeat; PCR, polymerase chain reaction; TAI, transcript accumulation index.

monolayer of Caco-2 cells help the Caco-2 cells develop M-cell-like characteristics. In order to confirm this, flow cytometric analysis was done with Caco-2 cells and Caco-2 + Raji cells co-culture, respectively. The analysis indicated that there was a significant change in Caco-2 cell surface, which is more close to M-cells. These data were also corroborated with other immunocytochemistry analysis indicating the co-cultured cells have expressed M-cellspecific characteristics confirming establishment of the in vitro M-cell model. In order to observe the functional activity of the M-cell, anti-GP2-conjugated FND was introduced in the M-cell model. Further, M-cell-mediated uptake and release study was performed to observe the uptake and successive release of nanodrug. The initial immunofluorescence study indicated that FND was taken up within first 2 hours of incubation. FND + GP2 showed higher uptake, indicating the M-cell-specific binding of anti-GP2 antibodies and adsorption of nanodrug. The absorption of FND and transport of FND by M-cells were observed at the lower chamber over a period of 48 hours. The fluorescence release study 
clearly indicated that these cells provided sustained release of nanodrug that was slower than that of the unformulated drug. We believe that the mechanism of accumulation and release of unformulated drug and nanoformulated drug may be different. In particular, nanoparticles should enter by endocytosis-mediated transport and release through recycling mechanism that is a slow process compared to trafficking of the free low-molecular drug. This sustained release process of nanodrug may be more therapeutically effective than that of the unformulated drug.

Overall, the data clearly indicate the potentials of M-cell to carry anti-HIV drug from the gut side to the GALT side. In this regard, the binding of anti-GP2 antibodies may improve targeting of drug molecules toward M-cell, and following that, inherent transmigration capability of M-cell takes the drug molecule to the other side of the barrier. The anti-HIV activity data indicated that treatment of cells with free drug or nanodrug significantly lowered levels of viral replication compared to untreated Raji cells. In case of free $\mathrm{EFV}$, there was an immediate decrease in viral replication as expected. However, rebound of viral p24 level within day 10 indicated failure of sustained inhibition of HIV replication in in vitro model. Whereas, in case of nanodrug, the immediate response was slower, but the subsequent sustained inhibition of viral replication was observed with consistent decline in $\mathrm{p} 24$ viral protein even on day 10 post infection. This observation definitely established the fact of the unique nests of the $\mathrm{F} 127 \mathrm{COOH}$ nanoformulation over free EFV drug.

Nonetheless, the present study also acknowledged the fact that macrophage or reticuloendothelial system can identify and clear the foreign substances or current nanodrug in both the blood and tissues. This is an important part of immune system that may bring obstacles for a nanoformulation directly applying in intravenous injection. However, the experimental design for current in vitro and future in vivo studies combines traditional oral drug formula with nano-technique in which nanoparticle may escape from macrophage tracking because of enteric coating capsule employed in our study. The nanodrug will be first encapsulated into an enteric coating capsule and administrated to mice. The present in vitro data verified the stability of nanoparticles under mimic intestine circumstance. Since the short period of drug release from nanodrug to the step of uptake by intestinal epithelium, this antibody digestion issue may be alleviated by our nanoformulation of enteric coating capsule. Because enteric capsule has the character of $\mathrm{pH}$ sensitivity, the nanoformulation will come out from cracked enteric capsule only at the intestine site and achieve the targeted drug delivery to increase therapeutic efficacy.

Therefore, we report the transmigration of anti-HIV drug molecule through M-cells, its potential release, and anti-HIV activity. This study will also serve as a model for future anti-HIV drug study with new formulations targeting toward GALT. In the recent years, few studies indicated the potential of M-cell for vaccine delivery and also its role in HIV transcytosis in the GALT ${ }^{47}$ However, this is the first report of using M-cells for anti-HIV drug delivery to the GALT and high-efficiency targeted drug delivery system. Nonetheless, the study could not establish the detailed nanodrug release profile compared to free drug and long-term stability of the drug in in vivo GALT model. Considering the limitations, the study still could establish evidence of delivery of nanodrug through M-cells, which is more therapeutically effective. Most importantly, this may also reduce the viral reservoir in the GALT compared to unformulated drug recommended at the clinic.

\section{Conclusion}

The main property of M-cells is the vertical translocation of particle from the intestine to lymphoid system. By utilizing this system, we have demonstrated the strong potential of F127COOH-EFV formulation to be used for high-efficiency targeted drug delivery system to the GALT. We also observed the steady release of nanodrug in the cell culture media compared to free drug. Considering the importance of GALT in HIV pathogenesis, this study will help us to significantly reduce the viral load of the GALT and improve the treatment outcome. It should now be possible to identify the mechanism of M-cell-based drug transport from the intestinal side to the GALT. The present study will help to design future oral nanodrug system to deliver anti-HIV drug with enteric-coated capsule that will survive the acidic digestion of stomach and deliver the drug directly to the GALT.

\section{Acknowledgments}

This work was supported by National Institutes of Health grants (1R01DA037838-01, 1R01DA027049, 1R21MH101025, and R01DA034547-01) and Herbert Wertheim College of Medicine developmental grant. We are sincerely grateful to Professor David Brayden and Tauseef Ahmad of University College Dublin for their assistance in developing M-cell model in vitro. We also thank Dr Helena Schmidtmayerova, Department of Biology, FIU, for her help in establishing human macrophage differentiation process and HIV infection. We also thank Deepa Roy for editing the manuscript. 


\section{Disclosure}

The authors report no conflicts of interest in this work.

\section{References}

1. Best BM, Letendre SL, Brigid E, et al; CHARTER Group. Low atazanavir concentrations in cerebrospinal fluid. AIDS. 2009;23(1):83-87.

2. Ding H, Wu F, Nair MP. Image-guided drug delivery to the brain using nanotechnology. Drug Discov Today. 2013;18(21-22):1074-1080.

3. Dane KY, Nembrini C, Tomei AA, et al. Nano-sized drug-loaded micelles deliver payload to lymph node immune cells and prolong allograft survival. J Control Release. 2011;156(2):154-160.

4. Kanmogne GD, Singh S, Roy U, et al. Mononuclear phagocyte intercellular crosstalk facilitates transmission of cell-targeted nanoformulated antiretroviral drugs to human brain endothelial cells. Int J Nanomedicine. 2012;7:2373-2388.

5. Lerner P, Guadalupe M, Donovan R, et al. The gut mucosal viral reservoir in HIV-infected patients is not the major source of rebound plasma viremia following interruption of highly active antiretroviral therapy. J Virol. 2011;85(10):4772-4782.

6. Varatharajan L, Thomas SA. The transport of anti-HIV drugs across blood-CNS interfaces: summary of current knowledge and recommendations for further research. Antiviral Res. 2009;82(2):A99-A109.

7. Pilakka-Kanthikeel S, Atluri VS, Sagar V, Saxena SK, Nair M. Targeted brain derived neurotropic factors (BDNF) delivery across the blood-brain barrier for neuro-protection using magnetic nano carriers: an in-vitro study. PLoS One. 2013;8(4):e62241.

8. Roy U, Bulot C, Honer zu Bentrup K, Mondal D. Specific increase in MDR1 mediated drug-efflux in human brain endothelial cells following co-exposure to HIV-1 and saquinavir. PLoS One. 2013;8(10):e75374.

9. Hondo T, Kanaya T, Takakura I, et al. Cytokeratin 18 is a specific marker of bovine intestinal M cell. Am J Physiol Gastrointest Liver Physiol. 2011;300(3):G442-G453.

10. Kerneis S, Bogdanova A, Kraehenbuhl J-P, Pringault E. Conversion by Peyer's patch lymphocytes of human enterocytes into $\mathrm{M}$ cells that transport bacteria. Science. 1997;277(5328):949-952.

11. Gullberg E, Leonard M, Karlsson J, et al. Expression of specific markers and particle transport in a new human intestinal M-cell model. Biochem Biophys Res Commun. 2000;279(3):808-813.

12. Manocha M, Pal PC, Chitralekha KT, et al. Enhanced mucosal and systemic immune response with intranasal immunization of mice with HIV peptides entrapped in PLG microparticles in combination with Ulex Europaeus-I lectin as M cell target. Vaccine. 2005; 23(48-49):5599-5617.

13. des Rieux A, Ragnarsson EG, Gullberg E, Preat V, Schneider YJ, Artursson P. Transport of nanoparticles across an in vitro model of the human intestinal follicle associated epithelium. Eur J Pharm Sci. 2005; 25(4-5):455-465.

14. Dhoro M, Zvada S, Ngara B, et al. CYP2B6*6, CYP2B6*18, body weight and sex are predictors of efavirenz pharmacokinetics and treatment response: population pharmacokinetic modeling in an HIV/AIDS and TB cohort in Zimbabwe. BMC Pharmacol Toxicol. 2015;16:4.

15. Olagunju A, Bolaji O, Amara A, et al. Breast milk pharmacokinetics of efavirenz and breastfed infants' exposure in genetically-defined subgroups of mother-infant pairs: an observational study. Clin Infect Dis. 2015;61(3):453-463.

16. Martín AS, Gómez AI, García-Berrocal B, et al. Dose reduction of efavirenz: an observational study describing cost-effectiveness, pharmacokinetics and pharmacogenetics. Pharmacogenomics. 2014;15(7): 997-1006.

17. Ding H, Yong K-T, Law W-C, et al. Non-invasive tumor detection in small animals using novel functional Pluronic nanomicelles conjugated with anti-mesothelin antibody. Nanoscale. 2011;3(4):1813-1822.

18. Ding H, Yong K-T, Roy I, et al. Bioconjugated PLGA-4-arm-PEG branched polymeric nanoparticles as novel tumor targeting carriers. Nanotechnology. 2011;22(16):165101.
19. Ding H, Sagar V, Agudelo M, et al. Enhanced blood-brain barrier transmigration using a novel transferrin embedded fluorescent magnetoliposome nanoformulation. Nanotechnology. 2014;25(5):055101. doi: 10.1088/0957-4484/25/5/055101(5).

20. Gandhi N, Saiyed ZM, Napuri J, et al. Interactive role of human immunodeficiency virus type 1 (HIV-1) clade-specific Tat protein and cocaine in blood-brain barrier dysfunction: implications for HIV-1-associated neurocognitive disorder. J Neurovirol. 2010;16(4):294-305.

21. Wu F, Bhansali SG, Tamhane M, et al. Noninvasive real-time fluorescence imaging of the lymphatic uptake of BSA-IRDye 680 conjugate administered subcutaneously in mice. J Pharm Sci. 2012; 101(5):1744-1754.

22. Agudelo M, Gandhi N, Saiyed Z, et al. Effects of alcohol on histone deacetylase 2 (HDAC2) and the neuroprotective role of trichostatin A (TSA). Alcohol Clin Exp Res. 2011;35(8):1550-1556.

23. Schmidtmayerova H, Alfano M, Nuovo G, Bukrinsky M. Human immunodeficiency virus type $1 \mathrm{~T}$-lymphotropic strains enter macrophages via a CD4- and CXCR4-mediated pathway: replication is restricted at a post entry level. J Virol. 1998;72(6):4633-4642.

24. Atluri VS, Kanthikeel SP, Reddy PV, Yndart A, Nair MP. Human synaptic plasticity gene expression profile and dendritic spine density changes in HIV-infected human CNS cells: role in HIV-associated neurocognitive disorders (HAND). PLoS One. 2013;8(4):e61399.

25. Atluri VS, Pilakka-Kanthikeel S, Samikkannu T, et al. Vorinostat positively regulates synaptic plasticity genes expression and spine density in HIV infected neurons: role of nicotine in progression of HIV-associated neurocognitive disorder. Mol Brain. 2014;7:37.

26. Yang SP, Liu WC, Lee KY, et al. Effectiveness of a reduced dose of efavirenz plus 2 NRTIs as maintenance antiretroviral therapy with the guidance of therapeutic drug monitoring. J Int AIDS Soc. 2014;17 (4 Suppl 3):19524.

27. Hurst SJ, Eifler A, Thaxton CS. Nanoparticle therapeutics: FDA approval, clinical trials, regulatory pathways, and case study. Methods Mol Biol. 2011;726:325-338.

28. Elluru M, Ma H, Hadjiargyrou M, Hsiao BS, Chu B. Synthesis and characterization of biocompatible hydrogel using Pluronics-based block copolymers. Polymer. 2013;54(8):2088-2095.

29. Simon T, Boca S, Biro D, Baldeck P, Astilean S. Gold-Pluronic coreshell nanoparticles: synthesis, characterization and biological evaluation. J Nanopart Res. 2013;15(4):1-8.

30. Chen L, Sha X, Jiang X, Chen Y, Ren Q, Fang X. Pluronic P105/F127 mixed micelles for the delivery of docetaxel against Taxol-resistant non-small cell lung cancer: optimization and in vitro, in vivo evaluation. Int J Nanomedicine. 2013;8:73-84.

31. Oerlemans C, Bult W, Bos M, Storm G, Nijsen JF, Hennink W. Polymeric micelles in anticancer therapy: targeting, imaging and triggered release. Pharm Res. 2010;27(12):2569-2589.

32. Hase K, Kawano K, Nochi T, et al. Uptake through glycoprotein 2 of FimH+ bacteria by $\mathrm{M}$ cells initiates mucosal immune response. Nature. 2009;462(7270):226-230.

33. Kunisawa J, Kurashima Y, Kiyono H. Gut-associated lymphoid tissues for the development of oral vaccines. Adv Drug Deliv Rev. 2012; 64(6):523-530.

34. Wallace SJ, Li J, Nation RL, Boyd BJ. Drug release from nanomedicines: selection of appropriate encapsulation and release methodology. Drug Deliv Transl Res. 2012;2(4):284-292.

35 . Hua S. Comparison of in vitro dialysis release methods of loperamideencapsulated liposomal gel for topical drug delivery. Int J Nanomedicine. 2014;9:735-744.

36. Du B, Li Y, Li X, Youmei A, Chen C, Zhang Z. Preparation, characterization and in vivo evaluation of 2-methoxyestradiol-loaded liposomes. Int J Pharm. 2010;384(1-2):140-147.

37. Li S, Hu J, Zhang L, et al. In-vitro and in-vivo evaluation of austocystin D liposomes. J Pharm Pharmacol. 2013;65(3):355-362.

38. Reddy ST, Rehor A, Schmoekel HG, Hubbell JA, Swartz MA. In vivo targeting of dendritic cells in lymph nodes with poly(propylene sulfide) nanoparticles. J Control Release. 2006;112(1):26-34. 
39. Ding $\mathrm{H}, \mathrm{Wu} \mathrm{F}$. Image guided biodistribution and pharmacokinetic studies of theranostics. Theranostics. 2012;2(11):1040-1053.

40. Ding $\mathrm{H}, \mathrm{Wu} F$. Image guided biodistribution of drugs and drug delivery. Theranostics. 2012;2(11):1037-1039.

41. Tan R, Niu M, Zhao J, Liu Y, Feng N. Preparation of vincristine sulfateloaded poly (butylcyanoacrylate) nanoparticles modified with pluronic F127 and evaluation of their lymphatic tissue targeting. J Drug Target. 2014;22(6):509-517.

42. Torchilin VP. Multifunctional nanocarriers. Adv Drug Deliv Rev. 2006; 58(14):1532-1555.

43. Ding H, Yong K-T, Roy I, et al. Gold nanorods coated with multilayer polyelectrolyte as contrast agents for multimodal imaging. JPhys Chem C. 2007;111(34):12552-12557.
44. Tahoun A, Mahajan S, Paxton E, et al. Salmonella transforms follicleassociated epithelial cells into $\mathrm{M}$ cells to promote intestinal invasion. Cell Host Microbe. 2012;12(5):645-656.

45. OikonomouE, Makrodouli E, Evagelidou M, Joyce T, Probert L, Pintzas A. BRAF(V600E) efficient transformation and induction of microsatellite instability versus $\operatorname{KRAS}(\mathrm{G} 12 \mathrm{~V})$ induction of senescence markers in human colon cancer cells. Neoplasia. 2009;11(11):1116-1131.

46. Haney MJ, Suresh P, Zhao Y, et al. Blood-borne macrophage-neural cell interactions hitchhike on endosome networks for cell-based nanozyme brain delivery. Nanomedicine (Lond). 2012;7(6):815-833.

47. Yuki Y, Nochi T, Kiyono H. Progress towards an AIDS mucosal vaccine: an overview. Tuberculosis (Edinb). 2007;87(suppl 1):S35-S44.

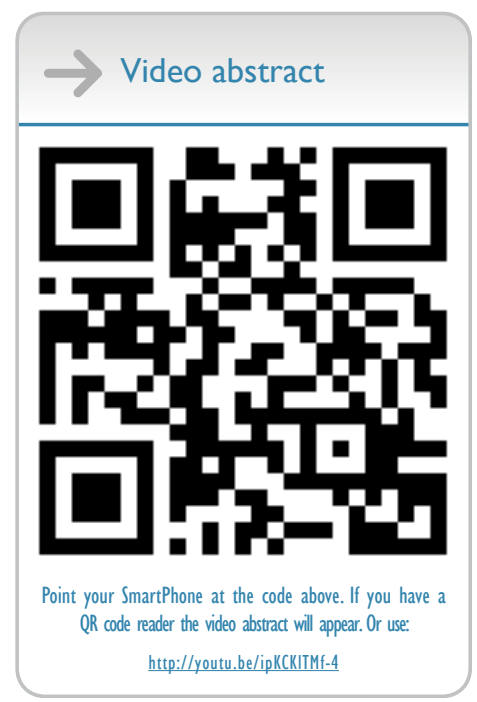

International Journal of Nanomedicine

\section{Publish your work in this journal}

The International Journal of Nanomedicine is an international, peerreviewed journal focusing on the application of nanotechnology in diagnostics, therapeutics, and drug delivery systems throughout the biomedical field. This journal is indexed on PubMed Central, MedLine, CAS, SciSearch ${ }^{\circledR}$, Current Contents ${ }^{\circledR} /$ Clinical Medicine,

Journal Citation Reports/Science Edition, EMBase, Scopus and the Elsevier Bibliographic databases. The manuscript management system is completely online and includes a very quick and fair peer-review system, which is all easy to use. Visit http://www.dovepress.com/ testimonials.php to read real quotes from published authors. 